\title{
In situ scanning tunneling microscopy study of 2- mercaptobenzimidazole local inhibition effects on copper corrosion at grain boundary surface terminations
}

\author{
Sagar B. Sharma, Vincent Maurice, ${ }^{*}$ Lorena H. Klein, Philippe Marcus ${ }^{*}$
}

PSL University, CNRS - Chimie ParisTech, Institut de Recherche de Chimie Paris (IRCP), Physical Chemistry of Surfaces Group, 11 rue Pierre et Marie Curie, 75005 Paris, France

\begin{abstract}
New insight on local inhibition effects of 2-mercaptobenzimidazole (MBI) on early stage intergranular corrosion of copper in hydrochloric acid solution is reported from in situ analysis at the nanometer scale and comparison with 2-mercaptobenzothiazole (MBT) effects in the same pre-adsorption and corrosion testing conditions. Macroscopic cyclic voltammetry analysis, including grains and grain boundary (GB) network, showed a passivation-like behavior in the $\mathrm{Cu}(\mathrm{I})$ oxidation range, specific to $\mathrm{MBI}$ since not observed with MBT and assigned to the anodic formation of a surface film of $\mathrm{Cu}(\mathrm{I})$-MBI reaction products protecting against dissolution. Electrochemical scanning tunneling microscopy analysis revealed net intergranular dissolution, mitigated by the imperfect protection provided by the anodically formed MBI layer. It also showed local accumulation of reaction products in the GB surface regions, blocking preferential dissolution. For random GBs, blocking by local accumulation of reaction products was dominant, in agreement with the expected higher reactivity of these GBs generating more $\mathrm{Cu}(\mathrm{I})$ ions under anodic polarization and thus less efficiently protected by the anodically formed MBI layer. For Coincidence Site Lattice (CSL) boundaries, mitigated net dissolution was more frequently observed. Coherent twins showed equally efficient inhibition in the GB surface region than on adjacent grains. MBI inhibition was less efficient than MBT inhibition with more $\mathrm{Cu}(\mathrm{I})$ reaction products generated on the grains to form a surface film and their preferential local accumulation more frequently observed in the GB surface regions.
\end{abstract}

Keywords: Intergranular corrosion; corrosion inhibition; 2-mercaptobenzimidazole (MBI); Copper; in situ STM; Nanometer scale

\footnotetext{
* Corresponding authors:

V. Maurice (vincent.maurice@ chimieparistech.psl.eu); P. Marcus (philippe.marcus@ chimieparistech.psl.eu)
} 


\section{Introduction}

Intergranular corrosion is a major form of degradation for polycrystalline metallic materials. It initiates locally at the surface termination of grain boundaries (GBs), and eventually propagates to attack the GB network, which can compromise the entire microstructure after penetration in the sub-surface. This form of localized corrosion can be combated by engineering polycrystals having the GB network the most resistant to corrosive attack. GB engineering is based on the knowledge of the relationships between crystallographic type and energy of grain boundaries and their susceptibility to intergranular corrosion, as developed from studies of GB engineered materials submitted to intergranular corrosion tests and studied with microstructural analytical techniques [1-26].

One efficient and widely applied mean to mitigate corrosion is to add inhibitors to the aggressive environment contacting the material. On copper and its alloys, azole derivatives such as the widely used and most studied benzotriazole (BTAH, $\mathrm{C}_{6} \mathrm{H}_{5} \mathrm{~N}_{3}$ ) but also mercaptoazoles derivatives such as 2-mercaptobenzothiazole $\left(\mathrm{MBT}, \mathrm{C}_{7} \mathrm{H}_{5} \mathrm{NS}_{2}\right)$ and 2-mercaptobenzimidazole (MBI, $\mathrm{C}_{7} \mathrm{H}_{6} \mathrm{~N}_{2} \mathrm{~S}$ ) have been shown to be effective corrosion inhibitors [27-30]. The MBT and MBI molecules, the latter being studied in this work, contain sulfur and nitrogen atoms that act as active sites that enable chemisorption to the metal substrate by strongly bonding, individually or concomitantly, to copper atoms, and thus form a stable and protective molecular film at the solid/liquid interface [30-44]. For MBI, the formation of a polymeric film has been proposed $[35,37,40,41,45]$ with the presence of $\mathrm{Cu}$ reaction products in the film - $\mathrm{Cu}-\mathrm{MBI}$ [37] or $\mathrm{Cu}_{2}-$ MBI [35] organo-metallic complexes have been suggested - conditioned by the initial surface 
state of copper, metallic or oxidized, prior to formation of the protective film [37], and also by the reactivity of copper during the film formation.

The efficiency of corrosion inhibitors to mitigate intergranular corrosion and the relationship between GB crystallographic type and inhibition mechanism remains to be investigated. Recently, this was studied on copper by investigating the effects of MBT on early stage intergranular corrosion at the surface termination of grain boundaries, i.e. before penetration in the sub-surface region and propagation [46]. Electro-Chemical Scanning Tunneling Microscopy (ECSTM) was used to study in situ in $\mathrm{HCl}$ acid solution the local alterations of the topmost surface of the metallic material at the nanometer scale. Among high angle GBs that are susceptible to intergranular corrosion in the absence of inhibitors $[2,6,8,9,11-13,16,22,26]$, only coherent twins - which are $\Sigma 3$ coincidence site lattice (CSL) boundaries with a $\{111\}$-oriented GB plane - did not show preferential intergranular reactivity compared to adjacent grains, which was assigned to the intrinsic resistance of these GBs also observed without the inhibitor $[3,13,22,26]$. Low $\Sigma$ Coincidence Site Lattice (CSL) boundaries were observed to be protected by the pre-adsorbed MBT layer against net preferential dissolution whereas high $\Sigma$ CSLs and random GBs were observed to react preferentially compared to grains. For these intrinsically more reactive boundaries, net dissolution, mitigated by the pre-adsorbed MBT layer, was observed as well as protection resulting from preferential formation of reaction products in the GB regions. For random GBs, protection by reaction products was more frequently observed but less stable upon repeated anodic cycling applied to force dissolution. 
Here, we report new insight for MBI and its local inhibiting effects at the surface termination of grain boundaries of various crystallographic types. ECSTM and CV (cyclic voltammetry) analysis was applied to microcrystalline copper in $\mathrm{HCl}$ aqueous acid solution in which no stable copper oxide is formed. Comparative analysis of the results obtained here with MBI with those obtained with MBT [46] in the same pre-adsorption and corrosion testing conditions provides deeper understanding on local inhibition mechanisms as well as their dependence on GB type and inhibiting molecule.

\section{Experimental}

The high purity microcrystalline copper samples were the same as in previous work $[19,22$ $26,47,48]$. From previous microstructural characterization $[22,23]$, texture is nearly random and $\sum 3 \mathrm{CSL}$ and random boundaries correspond to $66 \%$ and most of remaining $34 \%$ of the GB length, respectively. The surface was prepared by mechanical polishing (diamond spray, $0.25 \mu \mathrm{m}$ final grade) followed by electrochemical polishing (15 s in $66 \%$ orthophosphoric acid at $3 \mathrm{~V}$ versus $\mathrm{Cu}$ counter electrode) in order to remove the cold work layer and reveal the GB surface terminations.

An Agilent Technologies ECSTM system (PicoSPM base, Keysight STM S scanner, PicoScan 2100 controller, PicoStat bi-potentiostat and Picoscan software) was used. ECSTM cell, cleaning and tip preparation have been detailed elsewhere [49-53]. The ECSTM cell exposes a working electrode area of $0.16 \mathrm{~cm}^{2}$ to $\sim 350 \mu \mathrm{l}$ of electrolyte. Two Pt wires served as counter electrode and pseudo reference electrode $(+0.20 \mathrm{~V} / \mathrm{SHE})$. The $10 \mathrm{mM} \mathrm{HCl}(\mathrm{aq})(\mathrm{pH} 2)$ electrolyte was prepared from ultrapure $\mathrm{HCl}$ and Millipore water (resistivity $>18 \mathrm{M} \Omega \mathrm{cm}$ ) and 
non-deaerated. MBI was dissolved from the powder physical state at a concentration of $1 \mathrm{mM}$. After exposing the sample to the electrolyte at $-0.45 \mathrm{~V} / \mathrm{SHE}$, below the open-circuit potential value of $-0.35 \mathrm{~V} / \mathrm{SHE}$, the native oxide film formed after electropolishing was reduced by $\mathrm{CV}$ treament in the cathodic potential range as described before $[22,26]$. The cathodic peak associated with $\mathrm{Cu}(\mathrm{I})$ to $\mathrm{Cu}(0)$ reduction in the $\mathrm{CVs}$ was suppressed after two cycles, independently of the presence or absence of MBI in the solution during the cathodic reduction pre-treatment.

After reduction of the native oxide, the microcrystalline copper surface was imaged by ECSTM in the metallic state at $-0.45 \mathrm{~V} / \mathrm{SHE}$ to ensure localization of grain boundaries in the field of view. CV was also used to force anodic oxidation by cycling between the anodic and cathodic apexes of -0.18 and $-0.60 \mathrm{~V} / \mathrm{SHE}\left(1 \mathrm{mV} \mathrm{s}^{-1}\right)$, respectively, like applied in our MBT study [46]. Up to 4 cycles were applied and new ECSTM images of the same surface field of view were taken at $-0.45 \mathrm{~V} / \mathrm{SHE}$ after 2 and 4 cycles, thus enabling to follow the evolution of the local topography after electrochemical cycling. The images were acquired in the constant current mode. No filtering was used during acquisition and the recorded images were processed with the Gwyddion software [54]. At the surface, the terminations of the GB planes correspond to the GB edges. These GB edges and their immediate vicinity are referred to as the GB surface regions, easily identified in the STM images. The local difference in topographic height between the bottom of the GB surface regions and the two adjacent grains, hereafter called GB depth, was determined by line profile analysis as previously described [24,26,46]. 


\section{Results and discussion}

\subsection{Macroscopic MBI inhibition effects}

Cyclic voltammetry was applied with the same protocol as for the ECSTM study in order to characterize the effects of MBI on the macroscopic corrosion behavior. The exposed surface fraction of the grains being very large compared to that of the GB network, the macroscopic electrochemical response can be assigned to the surface properties of the grains. Figure 1(a) shows CVs started in the metallic state at $-0.45 \mathrm{~V} / \mathrm{SHE}$ after reduction of the native oxide. At $\mathrm{pH} 2$, no stable oxide is formed on copper and the $\mathrm{Cu}(\mathrm{I})$ ions dissolve as $\mathrm{CuCl}_{2}^{-}$in the investigated anodic potential range [55-58]. In the absence of MBI, anodic dissolution is observed for $\mathrm{E}>-0.35 \mathrm{~V} / \mathrm{SHE}$. The cathodic peak observed in the reverse scan corresponds to the reductive deposition of dissolved $\mathrm{Cu}(\mathrm{I})$ [26,58,59-63]. As discussed previously [46], the equivalent thickness of reacting copper can be deduced from the total positive current density (26885 $\left.\mu C \mathrm{~cm}^{-2}\right)$ using Eq. (1),

$$
\delta=\frac{q V_{m}}{z F}
$$

where $q$ is the charge density, $V_{m}$ the molar volume of metallic copper $\left(7.1 \mathrm{~cm}^{3} \mathrm{~mol}^{-1}\right), z$ the number of exchanged electrons (1), and $F$ the Faraday constant. The obtained value is $19.7 \mathrm{~nm}$, which indicates that a nanometer thick layer of material has reacted in these testing conditions. The CVs obtained in the presence of MBI are superimposed in Figure 1(a) and enlarged in Figure 1(b). The observed behavior depends on the presence or absence of MBI during the reduction pre-treatment of the native oxide. After pre-treatment in the absence MBI in the 
solution, the CV is flat showing highly efficient inhibition of the anodic dissolution of copper as well as of the cathodic activity. In this case, MBI adsorbs on the copper surface in the metallic state obtained after reduction of the native oxide, and controlled by setting the potential to 0.45 V/SHE while adding MBI to the electrolyte. The obtained CV shows that these preadsorption conditions optimize the inhibition efficiency of the molecular adsorbed layer in the potential range tested, due to formation of a molecular barrier efficiently blocking atomic transport across the interface.

After pre-treatment in the presence of $\mathrm{MBI}$ in the solution, the CV shows a higher copper electrochemical activity, however markedly reduced compared to that measured in the absence of the inhibitor. In this case, MBI pre-adsorbs on copper covered by the native oxide and the reduction process occurs in the presence of a surface layer of MBI. As a result, the $\mathrm{Cu}$ atoms dissociated from oxygen by electro-reduction may be captured by the molecular surface layer, resulting in the formation of a barrier film less effective to block atomic transport across the interface as indicated by the residual electrochemical response in the $\mathrm{Cu}(\mathrm{I})$ oxidation range. The anodic current also increases for $\mathrm{E}>-0.35 \mathrm{~V} / \mathrm{SHE}$ indicating that the anodic oxidation of copper and its transport across the interface leading to dissolution is initiated in the same potential range as in the absence of MBI. However, the current increase is much slower due to the mitigating effect of the MBI molecular layer pre-adsorbed on the surface. With increasing potential, a peak is observed at $-0.23 \mathrm{~V} / \mathrm{SHE}$. The anodic reaction decreases in intensity in a process similar to passivation. Copper transport and dissolution appear blocked by the anodic formation of a modified, compared to pre-adsorbed layer, but protective surface layer. The 


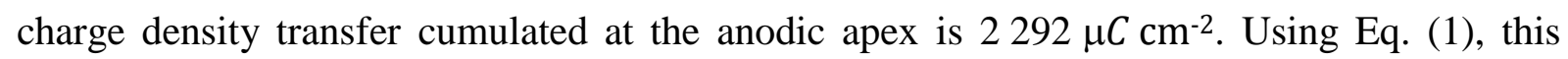
corresponds to $1.7 \mathrm{~nm}$ of copper having reacted and captured by the formation of the protective surface film grown at this stage (if one assumes no transient dissolution). Given that several monolayers of copper were consumed, it is suggested that this surface layer is $3 \mathrm{D}$ in thickness and constituted of $\mathrm{Cu}(\mathrm{I})-\mathrm{MBI}$ reaction products, possibly organic-metallic complexes [35,37], since grown in the $\mathrm{Cu}(\mathrm{I})$ oxidation range. It cannot be excluded that during the growth of the protective surface film some $\mathrm{Cu}(\mathrm{I})$ ions dissolved in the solution although no redeposition peak is observed in the subsequent cathodic scan.

In the reverse scan performed after reaching the anodic apex at $-0.18 \mathrm{~V} / \mathrm{SHE}$, no cathodic peak is observed in the range of -0.3 to $-0.50 \mathrm{~V} / \mathrm{SHE}$ unlike in the absence of the inhibitor. This is consistent with the grown surface layer blocking anodic dissolution and thus the reductive deposition of copper. The cathodic current increase observed for $\mathrm{E}<-0.30 \mathrm{~V} / \mathrm{SHE}$ may correspond to the electro-reduction of the surface film of $\mathrm{Cu}(\mathrm{I})$-MBI reaction products. A cathodic charge density transfer of $2107 \mu \mathrm{C} \mathrm{cm}-2$ is obtained from the integration of the negative current density measured during cycling, which corresponds to an equivalent thickness of $1.55 \mathrm{~nm}$ of reacting copper. This value confirms the 3D thickness of the protecting surface layer grown by anodic oxidation of copper in the presence of the MBI inhibitor.

The CV previously obtained in the same testing conditions after pre-treatment in the presence of MBT [46] is reproduced in Figure 1(b) for comparison. The surface is much less reactive than in the presence of MBI with no anodic peak indicative of anodic formation of a 3D layer constituted of $\mathrm{Cu}(\mathrm{I})-\mathrm{MBT}$ reaction products. The total measured positive current density is 
$36 \mu C \mathrm{~cm}^{-2}$, corresponding to only a fraction of a monolayer of copper $(0.03 \mathrm{~nm}$ equivalent thickness) having reacted [46]. For the same conditions of pre-treatment of the surface, comparison between the two molecules shows higher anodic inhibition efficiency for MBT than for MBI. For MBT, the pre-adsorbed molecular layer nearly fully blocks the macroscopic anodic activity. It can be deduced that the surface of grains is fully protected by the interfacial molecular layer in the test conditions, and that the residual activity may be associated to the most reactive (i.e. imperfectly protected) sites, including the GB network. For MBI, the preadsorbed molecular layer only mitigates anodic oxidation, leading to a passivation-like behavior with the buildup of a protective 3D surface layer of $\mathrm{Cu}(\mathrm{I})$-MBI reaction products. This surface layer forms at the surface of the grains as deduced from the macroscopic electrochemical response. It also forms in the GB regions as deduced from the local analysis of the topography variations discussed hereafter.

\subsection{Local MBI inhibition effects at grain boundaries}

Figure 2(a) shows a typical local area at the topmost surface of microcrystalline copper as obtained in situ after reduction of the native oxide in the presence of MBI. ECSTM images of this local microstructure could be repeatedly obtained and after 2 (Figure 2(b)) and 4 (Figure 2(c)) CVs. Grains and sub-grains delimited by grain boundaries are observed at varying topographic levels owing to differences of local reactivity during surface preparation. In each image, the depth at the bottom of the GB region could be geometrically measured in the same local position after 0,2 and $4 \mathrm{CVs}$ for 74 sites. A typical example of the line profile obtained 
for site \#1 in Figure 2 before and after 2 and 4 CVs is shown in Figure 3. In this example, no variation of the GB depth is observed.

The comparative analysis of the GB depth before and after the CV treatments in the 74 sites revealed 5 types of local intergranular behavior: i) unchanged GB depth, ii) repeated increase, iii) repeated decrease, iv) decrease followed by increase, and v) increase followed by decrease. The distribution of these observed behaviors is shown in Figure 4.

The 5 sites showing no specific local behavior caused by intergranular corrosion after 2 and 4 CVs are labelled 1 to 5 in Figure 4(a). The bar graph of the GB depth confirms no net variation of the depth of the GB region compared to the adjacent grains (Figure 4(b)). In the absence of inhibitors, such an absence of preferential local intergranular reactivity is typical of coherent twins ( $\Sigma 3$ CSL with a $\{111\}$-oriented GB plane) $[3,13,22,26,46]$. In the present case, it is observed along two parallel GBs separating a narrow sub-grain (sites 3 to 5), a configuration typical of $\Sigma 3$ coherent twins. It is also observed for sites 1 and 2 also located along two parallel GBs and separating a wider sub-grain. At these sites, the absence of preferential local reactivity is thus assigned to the intrinsic intergranular properties of the $\Sigma 3$ coherent twins rather than to a local effect of the MBI inhibitor. The surface layer of $\mathrm{Cu}(\mathrm{I})-\mathrm{MBI}$ reaction products formed indifferently in the GB region and on the adjacent grains, and the $\Sigma 3$ coherent twins did not react preferentially owing to their intrinsic resistance against intergranular corrosion (Figure 5(a)).

The 10 sites showing a repeated net increase of the depth of the GB region after 2 and 4 CVs are labelled 6 to 15 in Figure 4(a) and (c). In the absence of formation of a passive film, the 
increase of the GB depth is indicative of the preferential local consumption of the material by irreversible and faster dissolution than on the adjacent grains as previously observed for early stage intergranular corrosion of copper in $1 \mathrm{mM} \mathrm{HCl}(\mathrm{aq})$ in the absence of inhibitor [22,26]. In the present case, a surface layer of $\mathrm{Cu}(\mathrm{I})-\mathrm{MBI}$ reaction products is formed as shown by the $\mathrm{CV}$ analysis. The formation of a thinner layer in the GB regions than on the adjacent grains would result in an increase of the GB depth. However, this is not consistent with the preferential reactivity expected in the GB regions. In contrast, the formation in the GB regions of a surface layer less efficiently mitigating anodic dissolution than on the adjacent grains is consistent with the more reactive character of the GBs, and would result in an increase of the GB depth owing to the preferential consumption of copper in the GBs regions (Figure 5(b)). Among the $10 \mathrm{~GB}$ sites where preferential although mitigated irreversible dissolution is observed, only site 12 can correspond to a $\Sigma 3$ coherent twin (the same as for site 2 ). This coherent twin is possibly locally deviated from the perfect geometry since exhibiting local preferential dissolution [26]. Among the 9 other sites, site 14 is located at a short and straight boundary, assigned to a low $\Sigma$ CSL boundary. Sites 7 to 9 are located along straight segments of a GB whose morphology is locally straight or curved and assigned to a high $\Sigma$ CSL. Sites 6,10,11, 13 and 15 belong to GBs with curved morphologies indicating their random character. For these high $\Sigma$ CSL and random boundaries, local intergranular irreversible dissolution is observed but mitigated by the MBI surface layer given the relatively small increase of the GB depth.

The repeated net decrease of the depth of the GB region after 2 and $4 \mathrm{CV}$ s could be measured in 16 sites, labelled 16 to 31 in Figure 4(a) and (d). The decrease of the GB depth is consistent 
with the local accumulation of reaction products, more important in the GB region because of the locally higher reactivity. Such a local GB behavior has been observed by ECSTM for copper passivated in $0.1 \mathrm{M} \mathrm{NaOH}(\mathrm{aq})$ and attributed to a locally thicker $\mathrm{Cu}(\mathrm{I})$ passive oxide film formed in the $\mathrm{GB}$ regions $[24,25,64]$. In $10 \mathrm{mM} \mathrm{HCl}(\mathrm{aq})+1 \mathrm{mM} \mathrm{MBI}$, the electrochemical response is indicative of a passivation-like behavior not observed in the absence of MBI. More copper would react in the GB region during anodic polarization leading to the formation of a thicker layer of $\mathrm{Cu}(\mathrm{I})$ reaction products than on the adjacent grains. The process would be repeated at each treatment cycle thus leading to the thickness increase of the film formed in the GB regions (Figure 5(c)). This formation of a thicker film of $\mathrm{Cu}(\mathrm{I})$ reaction products than on the adjacent grains is observed at sites 16, 28 and 29 along straight GBs that can be assigned to low $\Sigma$ CSL GBs. It is also observed at site 19 along the same straight GB segment as at sites 7 and 8 and corresponding to a high $\Sigma$ CSL, thereby showing that the inhibitor effect may be dependent on the local structure along the same GB edge. Sites 17, 18, 20-27, 30 and 31 all belong to random GBs characterized by curved morphologies. It is at such GBs that the largest decrease of the GB depth is observed (sites 21, 24, 30 and 31), which is consistent with more copper being consumed in these more reactive GBs leading to increased accumulation of $\mathrm{Cu}(\mathrm{I})$ MBI reaction products with formation of a thicker film.

Figure 4(a) and (e) shows the 34 GB sites, labelled 32 to 65, where, after 2 CVs, the behavior was first characterized by a decrease of the GB depth and subsequently, after $4 \mathrm{CVs}$, by an increase. Like for the GB sites 16 to 31 discussed above, the initial decrease of the GB depth is assigned to the preferential accumulation in the $\mathrm{GB}$ region of $\mathrm{Cu}(\mathrm{I})$ reaction products leading 
to the formation of a locally thicker surface layer than on the adjacent grains. The subsequent increase of the GB depth after 2 more CVs is indicative of net dissolution by anodic oxidation. This unstable behavior suggests that the thicker layer of $\mathrm{Cu}(\mathrm{I})$ reaction products formed in the GB regions first provides local protection against anodic dissolution, like observed on the grains by $\mathrm{CV}$. However, this initial protection provided by the surface layer is not stable since altered during the subsequent $\mathrm{CV}$ treatments as shown by the increase of the GB depth resulting from net dissolution (Figure 5(d)). Among the GB sites where this behavior is observed, site 48 can be assigned to a $\Sigma 3$ coherent twin of locally imperfect geometry like at site 12 . Site 33 can be assigned to a low $\Sigma$ CSL boundary, the same as site 16 discussed above. Site 42 belongs to a straight segment that can be assigned to a high $\Sigma$ CSL boundary. Note that at these 3 sites the GB depth variations are small indicating little alterations of the local early intergranular corrosion behavior. All the other 31 sites belong to curved or locally curved boundaries assigned to random boundaries. Among them only a minority of 10 sites $(37,38,40,43,44,47$, $50,58,61$ and 62 ) show an increase of the GB depth after $4 \mathrm{CV}$ s to a value higher that the initial value measured before cycling, indicating a pronounced alteration of the transient protection brought by the formation of the surface layer of reaction products.

We found $9 \mathrm{~GB}$ sites where the behavior was first characterized by an increase of the GB depth after $2 \mathrm{CVs}$ and subsequently by a decrease after $4 \mathrm{CVs}$. They are labelled 66 to 74 in Figure 4(a) and (f). Like for sites 6 to 15 discussed above, we assign the increase of the GB depth measured after $2 \mathrm{CV}$ s to net irreversible dissolution, less mitigated by the surface layer of $\mathrm{Cu}(\mathrm{I})$ reaction products at the GBs than on the adjacent grains. After 2 more CVs, the preferential 
accumulation of $\mathrm{Cu}(\mathrm{I})$ reaction products in the $\mathrm{GB}$ region decreases the $\mathrm{GB}$ depth owing to the formation of a thicker surface layer than on the adjacent grains. In this case, the repeated alterations of the surface layer brought by the $\mathrm{CV}$ treatment promote a delayed protection in the GB regions (Figure 5(e)). All GB sites except one (site 66) at which this behavior was observed belong to curved or locally curved boundaries characteristic of random GBs. Site 66 belongs to short and straight boundary, assigned to a low $\Sigma$ CSL boundary.

\subsection{Local MBI inhibition effects according to GB type}

The 5 types of local intergranular corrosion behavior observed in this work in the presence of MBI and their occurrences according to GB crystallographic type are compiled in Table 1 and Figure 6. The distribution of behavior observed with MBT [46] is also reported in Figure 6 for comparison.

In most cases and independently of the presence of the MBI or MBT inhibitors in the solution, the $\Sigma 3$ coherent twins showed no preferential intergranular reactivity compared to the adjacent grains. This is in agreement with intrinsic resistance of these grain boundaries to intergranular corrosion $[3,13,22,26]$, and thus equally efficient inhibition in the GB surface region than on adjacent grains can be concluded for the $\Sigma 3$ coherent twins. Local preferential reactivity was observed in two cases despite the presence of MBI, likely owing to the local deviation of the grain boundary plane from the perfect geometry as observed previously in the absence of inhibitor [26]. In these cases, the anodically formed surface layer of $\mathrm{Cu}(\mathrm{I})-\mathrm{MBI}$ corrosion products provided imperfect or only transient protection against anodic dissolution. 
All other types of grain boundaries showed preferential reactivity. For the most reactive random GBs, protection by accumulation of reaction products was found to largely predominate protection by mitigated dissolution. For MBI, with which a passivation-like behavior of the grains is observed by $\mathrm{CV}$, this mode of protection results from the formation of a thicker film of $\mathrm{Cu}(\mathrm{I})$ corrosion products in the GB region than on the adjacent grains. For MBT, with which no passivation-like anodic behavior of the grains is observed, this mode of protection results from the local accumulation of $\mathrm{Cu}(\mathrm{I})$ corrosion products in the $\mathrm{GB}$ region. With both inhibitors, the preferential formation of corrosion products in the GB region is consistent with more intense activity occurring at the surface terminations of random GBs, as expected from the ill-defined crystallographic character of these boundaries, and producing upon anodic polarization more $\mathrm{Cu}(\mathrm{I})$ corrosion products than in CSL boundaries. With MBI, as well as with MBT, the major part of the measured random GB sites did not show stable protection after repeated anodic polarization, showing the fragile protectiveness provided by the reaction products accumulated in the surface regions of the random GBs.

Much fewer occurrences of the locally observed intergranular behavior could be associated with CSL boundaries. For the high $\Sigma$ CSLs, protection by a thicker layer of $\mathrm{Cu}(\mathrm{I})-\mathrm{MBI}$ corrosion products is also observed but mitigated dissolution by the anodically formed MBI layer is more frequent, in agreement with a lower reactivity of high $\Sigma$ CSLs compared to most random GBs. A more balanced distribution of these two types of local inhibition effects was also observed with MBT. For low $\Sigma$ CSLs, protection by a thicker layer of $\mathrm{Cu}(\mathrm{I})-\mathrm{MBI}$ corrosion products is more frequent than mitigated dissolution by the MBI layer. This suggests that some CSL 
boundaries could be initially as reactive as random $\mathrm{GBs}$ for forming $\mathrm{Cu}(\mathrm{I})-\mathrm{MBI}$ corrosion products. A larger fraction of the low CSLs than of random GBs would form a stable protective layer of corrosion products.

\section{Conclusions}

The local inhibiting effects of MBI on the initial stages of intergranular corrosion of copper were studied in situ by ECSTM in $10 \mathrm{mM} \mathrm{HCl(aq)} \mathrm{acid} \mathrm{solution.} \mathrm{Macroscopic} \mathrm{analysis} \mathrm{by} \mathrm{CV}$ of the grains and $\mathrm{GB}$ network electrochemical response in the $\mathrm{Cu}(\mathrm{I})$ oxidation range confirmed that MBI inhibits the active dissolution of copper and showed that the inhibition efficiency markedly depends on the conditions of pre-adsorption of the molecule. If pre-adsorbed on the surface in the metallic state, anodic as well as cathodic activity is suppressed, most likely by formation of a homogeneous barrier molecular film efficiently blocking atomic transport across the interface. If pre-adsorbed on the surface covered by its native oxide and subsequently reduced, the residual activity is higher and characteristic of a passivation-like behavior assigned to the anodic formation of a protective surface film of $\mathrm{Cu}(\mathrm{I})$-MBI reaction products.

Local ECSTM analysis at the surface termination of the GB network showed no preferential intergranular corrosion of the $\Sigma 3$ coherent twins compared to grains, in agreement with their intrinsic resistance to intergranular corrosion. All other types of GBs reacted preferentially compared to adjacent grains. They showed preferential dissolution mitigated by the imperfect protection provided by the anodically formed $\mathrm{Cu}(\mathrm{I})$-MBI surface film, or preferential accumulation of $\mathrm{Cu}(\mathrm{I})$ reaction products protecting the $\mathrm{GB}$ surface regions against intergranular dissolution. Local GB protection by preferential accumulation of $\mathrm{Cu}(\mathrm{I})$ reaction products was 
observed to be transient, delayed or stable in the conditions of repeated anodic cycling applied to force anodic oxidation. For CSL grain boundaries other than $\Sigma 3$ coherent twins, mitigated preferential dissolution occurred more frequently than blocking by accumulated reaction products, indicating more efficient protection by the anodically formed MBI surface layer. For the random boundaries, local protection by preferential accumulation of $\mathrm{Cu}(\mathrm{I})$ reaction products was dominant like previously observed with MBT. This is assigned to the intrinsically more reactive character of the random GBs, less efficiently protected by the anodically formed MBI layer and with the generation of more $\mathrm{Cu}(\mathrm{I})$ ions under anodic polarization resulting in the local accumulation of $\mathrm{Cu}(\mathrm{I})-\mathrm{MBI}$ reaction products.

Comparison with MBT effects studied in the same pre-adsorption and testing conditions shows less efficient inhibition by $\mathrm{MBI}$, with more $\mathrm{Cu}(\mathrm{I})$ reaction products generated on the grains to form a surface film and the preferential accumulation of reaction products more frequently observed in the GB surface regions.

\section{Acknowledgments}

This project has received funding from the European Research Council (ERC) under the European Union's Horizon 2020 research and innovation programme (ERC Advanced Grant agreement No 741123). 


\section{References}

[1] J. Mieluch, M. Smialowski, The Behaviour of Grain Boundaries in Iron During Anodic Polarization in Ammonium Nitrate Solution, Corrosion Science 4 (1964) 237-243.

[2] P. Lin, G. Palumbo, U. Erb, K.T. Aust, Influence of Grain Boundary Character Distribution on Sensitization and Intergranular Corrosion of Alloy 600, Scripta Metallurgica et Materiala 33 (1995) 1387-1392.

[3] A. Vinogradov, T. Mimaki, S. Hashimoto, R.Z. Valiev, On the Corrosion Behaviour of Ultra-Fine Grain Copper, Scripta Materialia 41 (1999) 316-326.

[4] L. Lu, M.L. Sui , K. Lu, Superplastic Extensibility of Nanocrystalline Copper at Room Temperature, Science 287 (2000) 1463-1466.

[5] V.Y. Gerrtsman, S.M. Gruemer, Study of Grain Boundary Character Along Intergranular Stress Corrosion Crack Paths in Austenitic Alloys, Acta Materialia 49 (2001) 1589-1598.

[6] S.H. Kim, U. Erb, K.T. Aust, G. Palumbo, Grain Boundary Character Distribution and Intergranular Corrosion Behavior in High Purity Aluminum, Scripta Materialia 44 (2001) 835-839.

[7] H. Miyamoto, K. Yoshimura, T. Mimaki, M. Yamashita, Behavior of Intergranular Corrosion of <011> Tilt Grain Boundaries of Pure Copper Bicrystals, Corros. Sci. 44 (2002) 1835-1846. Acta Materialia 50 (2002) 2331-2341.

[8] M. Shimada, H. Kokawa, Z.J. Wang, Y.S. Sato, I. Karibe, Optimization of grain boundary character distribution for intergranular corrosion resistant 304 stainless steel by twininduced grain boundary engineering, Acta Materialia 50 (2002) 2331-2341.

[9] E.M. Lehockey, A.M. Brennenstuhl, I. Thompson, On the relationship between grain boundary connectivity, coincident site lattice boundaries, and intergranular stress corrosion cracking, Corrosion Science 46 (2004) 2383-2404.

[10] V. Randle, 'Special' Boundaries and Grain Boundary Plane Engineering, Scripta Materialia. 54 (2006) 1011-1015.

[11] S. Xia, B. Zhou, W. Chen, Effect of single-step strain and annealing on grain boundary character distribution and intergranular corrosion in Alloy 690, Journal of Material Science 43 (2008) 2990-3000

[12] R. Jones, V. Randle, Sensitisation behaviour of grain boundary engineered austenitic stainless steel, Materials Science and Engineering A 527 (2010) 4275-4280.

[13] K. D. Ralston, N. Birbilis, Effect of Grain Size on Corrosion: A Review, Corrosion 66 (2010) 075005-075005-13.

[14] CL Changliang, S.Xi, H. Li, TG. Liu, BX. Zhou, WJ. Chen, N. Wang, Ning, Improving the intergranular corrosion resistance of 304 stainless steel by grain boundary network control, Corrosion Science 53 (2011) 1880-1886.

[15] C. Luo, X. Zhou, G.E. Thompson, A.E. Hughes, Observations of intergranular corrosion in AA2024-T351: The influence of grain stored energy, Corrosion Science 61 (2012) 3544. 
[16] Sunil Kumar B., Balla Sai Prasad, Vivekanand Kain, Jayanth Reddy, Methods for making alloy 600 resistant to sensitization and intergranular corrosion, Corrosion Science 70 (2013) 55-61.

[17] Y. Takehara, H. Fujiwara, H Miyamoto, "Special" to "general" transition of intergranular corrosion in Sigma 3\{111\} grain boundary with gradually changed misorientation, Corrosion Science 77 (2013) 171-175.

[18] A. Stratulat, J.A. Duff, T.J. Marrow, T. James, Grain boundary structure and intergranular stress corrosion crack initiation in high temperature water of a thermally sensitised austenitic stainless steel, observed in situ, Corrosion Science 85 (2014) 428435 .

[19] E. Martinez-Lombardia, Y. Gonzalez-Garcia, L. Lapeire, I. De Graeve, K. Verbeken, L. Kestens, J. Mol, H. Terryn, Scanning Electrochemical Microscopy to Study the Effect of Crystallographic Orientation on the Electrochemical Activity of Pure Copper, Electrochimica Acta 116 (2014) 89-96.

[20] B.V. Mahesh, R.K. Singh Raman, Role of Nanostructure in Electrochemical Corrosion and High Temperature Oxidation: A Review, Metallic Materials Transactions A 45A (2014) 5799-5822.

[21] N. Srinivasan, V. Kain, N. Birbilis, K.V. Mani Krishna, S. Shekhawat, I. Samajdar, Near boundary gradient zone and sensitization control in austenitic stainless steel, Corrosion Science 100 (2015) 544-555.

[22] E. Martinez-Lombardia, L. Lapeire, V. Maurice, I. De Graeve, K. Verbeken, L.H. Klein, L. Kestens, P. Marcus, H. Terryn, In Situ Scanning Tunneling Microscopy Study of the Intergranular Corrosion of Copper, Electrochemistry Communications 41 (2014) 1-4.

[23] E. Martinez-Lombardia, V. Maurice, L. Lapeire, I. De Graeve, K. Verbeken, L.H. Klein, L. Kestens, P. Marcus, H. Terryn, In Situ Scanning Tunneling Microscopy Study of Grain-Dependent Corrosion on Microcrystalline Copper., Journal of Physical Chemistry C 118 (2014) 25421-25428.

[24] H. Chen, V. Maurice, L.H. Klein, L. Lapeire, K. Verbeken, H. Terryn, P. Marcus, Grain Boundary Passivation Studied by In Situ Scanning Tunneling Microscopy on Microcrystalline Copper, Journal of Solid State Electrochemistry 19 (2015) 3501-3509.

[25] H. Chen, M. Bettayeb, V. Maurice, L.H. Klein, L. Lapeire, K. Verbeken, H. Terryn, P. Marcus, Local passivation of metals at grain boundaries: In situ scanningtunneling microscopy study on copper, Corrosion Science 111 (2016) 659-666.

[26] M. Bettayeb, V. Maurice, L.H. Klein, L. Lapeire, K. Verbeken, P. Marcus, Nanoscale Intergranular Corrosion and Relation With Grain Boundary Character as Studied In Situ on Copper, Journal of the Electrochemical Society 165 (2018) C835-C841.

[27] M. Antonijevic, M. Petrovic Mihajlovic, Copper corrosion inhibitors. A review, International Journal of Electrochemical Science 3 (1) (2008) 1-28.

[28] M. M. Antonijevic, S. M. Milic, M. B. Petrovic, Films formed on copper surface in chloride media in the presence of azoles, Corrosion Science 51 (2009) 1228-1237.

[29] M. Petrovic Mihajlovic, M. Antonijevic, Copper corrosion inhibitors. period 2008-2014. a review, International Journal of Electrochemical Science 10 (2015) 1027-1053. 
[30] T. Shahrabi, H. Tavakholi, M. G. Hosseini, Corrosion inhibition of copper in sulphuric acid by some nitrogen heterocyclic compounds, Anti-Corrosion Methods and Materials 54 (2007) 308-313.

[31] P. M. Niamien, F. K. Essy, A. Trokourey, A. Yapi, H. K. Aka, D. Diabate, Correlation between the molecular structure and the inhibiting effect of some benzimidazole derivatives, Materials Chemistry and Physics 619136 (2012) 59-65.

[32] M. Finsgar, 2-mercaptobenzimidazole as a copper corrosion inhibitor: Part i. long-term immersion, 3D-profilometry, and electrochemistry, Corrosion Science 72 (2013) 82-89.

[33] I. Milosev, N. Kovacevic, J. Kovac, A. Kokalj, The roles of mercapto, benzene and methyl groups in the corrosion inhibition of imidazoles on copper: I. experimental characterization, Corrosion Science 98 (2015) 107-118.

[34] G. Zerjav, I. Milosev, Protection of copper against corrosion in simulated urban rain by the combined action of benzotriazole, 2-mercaptobenzimidazole and stearic acid, Corrosion Science 98 (2015) 180-191.

[35] D. Chadwick, T. Hashemi, Electron spectroscopy of corrosion inhibitors: Surface film formed by 2-mercaptobenzothiazole and 2-mercaptobenzimidazole on copper, Surface Science 89 (1-3) (1979) 649-659.

[36] Y. Tooru, An X-ray photoelectron spectroscopic study of several metal complexes of 2mercaptobenzimidazole and 2-mercaptobenzoxazole, The Chemical Society of Japan 53 (5) (1980) 1449-1450.

[37] G. Xue, X.-Y. Huang, J. Dong, J. Zhang, The formation of an effective anti-corrosion film on copper surfaces from 2-mercaptobenzimidazole solution, Journal of Electroanalytical Chemistry 310 (1991) 139-148.

[38] G. Xue, X. Huang, J. Ding, Surface reaction of 2-mercaptobenzimidazole on metals and its application in adhesion promotion, Journal of the Chemical Society Faraday Transactions 87 (8) (1991) 1229-1232.

[39] G. Xue, Q. Dai, SERS and IR studies of the reaction of an oxidized surface and an etched surface of copper with 2-mercaptobenzimidazole, Spectroscopy Letters 27 (3) (1994) 341-351.

[40] F. Perrin, J. Pagetti, Characterization and mechanism of direct film formation on a $\mathrm{Cu}$ electrode through electro-oxidation of 2-mercaptobenzimidazole, Corrosion science 40 (10) (1998) 1647-1662.

[41] B. Trachli, M. Keddam, H. Takenouti, A. Srhiri, Protective effect of electropolymerized 2-mercaptobenzimidazole upon copper corrosion, Progress in Organic Coatings 44 (2002) 17-23.

[42] J. Izquierdo, J. J. Santana, S. Gonzalez, R. M. Souto, Scanning microelectrochemical characterization of the anti-corrosion performance of inhibitor films formed by 2mercaptobenzimidazole on copper, Progress in Organic Coatings 74 (3) (2012) 526\{533.

[43] M. Finsgar, 2-mercaptobenzimidazole as a copper corrosion inhibitor: Part ii. surface analysis using X-ray photoelectron spectroscopy, Corrosion Science 72 (2013) 90-98.

[44] X. Wu, F. Wiame, V. Maurice, P. Marcus, 2-mercaptobenzimidazole films formed at ultra-low pressure on copper: adsorption, thermal stability and corrosion inhibition performance, Applied Surface Science 527 (2020) 146814. 
[45] D. quan Zhang, L. xin Gao, G. ding Zhou, Inhibition of copper corrosion in aerated hydrochloric acid solution by heterocyclic compounds containing a mercapto group, Corrosion Science 46 (2004) 3031-3040.

[46] S.B. Sharma, V. Maurice, L.H. Klein, P. Marcus, Local inhibition by 2mercaptobenzothiazole of early stage intergranular corrosion of copper, Journal of the Electrochemical Society 167 (2020) 161504.

[47] L. Lapeire, E. Martinez Lombardia, K. Verbeken, I. De Graeve, L. Kestens, H. Terryn, Effect of Neighboring Grains on the Microscopic Corrosion Behavior of a Grain in Polycrystalline Copper, Corrosion Science 67 (2013) 179-183.

[48] L. Lapeire, E. Martinez Lombardia, K. Verbeken, I. De Graeve, L. Kestens, H. Terryn, Structural Dependence of Gold Deposition by Nanoplating in Polycrystalline Copper, Journal of Materials Science 49 (2014) 3909-3916.

[49] D. Zuili, V. Maurice, P. Marcus, Surface Structure of Nickel in Acid Solution Studied by In Situ STM, Journal of the Electrochemical Society 147 (2000) 1393-1400.

[50] A. Seyeux, V. Maurice, L. H. Klein, P. Marcus, In Situ STM Study of the Initial Stages of Growth and of the Structure of the Passive Film on Ni(111) in $1 \mathrm{mM} \mathrm{NaOH}(\mathrm{aq})$, Journal of Solid State Electrochemistry 9 (2005) 337-346.

[51] A. Seyeux, V. Maurice, L. H. Klein, P. Marcus, In Situ STM Study of the Effect of Chloride on the Growth Mechanism and Structure of the Passive Film on Nickel in Alkaline Solution, Journal of the Electrochemical Society 153 (2006) B453-463.

[52] V. Maurice, L. H. Klein, H.-H. Strehblow, P. Marcus, In situ STM Study of the Surface Structure, Dissolution and Early Stages of Electrochemical Oxidation of the $\operatorname{Ag}(111)$ Electrode, Journal of Physical Chemistry C 111 (2007) 16351-16361.

[53] N. Li, V. Maurice, L. H. Klein, P. Marcus, Structure and Morphology Modifications of Silver Surface in the Early Stages of Sulphide Growth in Alkaline Solution, Journal of Physical Chemistry C 116 (2012) 7062-7072.

[54] Gwyddion - Free SPM (AFM, SNOM/NSOM, STM, MFM ...) data analysis software. http://gwyddion.net/

[55] H.-H. Strehblow, B. Titze, The Investigation of the Passive Behaviour of Copper in Weakly Acid and Alkaline Solutions and the Examination of the Passive Film by Esca and ISS, Electrochimica Acta 25 (1980) 839-850.

[56] Y. Feng, K.S. Siow, W.K.Teo, K.L.TanL, A.K Hsieh, Corrosion Mechanisms and Products of Copper in Aqueous Solutions at Various pH Values, Corrosion 53 (1997) 389-398.

[57] B. Beverskog, I. Puigdomenech, Pourbaix Diagrams for the System Copper-Chlorine at 5-100 C. SKI, Nyköping, 1998

[58] O. Magnussen, L. Zitzler, B. Gleich, M. Vogt, R.J. Behm, In-Situ Atomic-Scale Studies of the Mechanisms and Dynamics of Metal Dissolution by High-Speed STM, Electrochimica Acta 46 (2001) 3725-3733.

[59] M. Kruft, B. Wohlmann, C. Stuhlmann, K. Wandelt, Chloride Adsorption on $\mathrm{Cu}(111)$ Electrodes in Dilute HCl Solutions, Surface Science 377 (1997) 601-604. 
[60] M. Vogt, A. Lachenwitzer, O. Magnussen, R.J. Behm, In-Situ STM Study of the Initial Stages of Corrosion of $\mathrm{Cu}(100)$ Electrodes in Sulfuric and Hydrochloric Acid Solution. Surface Science 399 (1998) 49-69.

[61] L.-J. Wan, K. Itaya, In Situ Scanning Tunneling Microscopy of Cu(110): Atomic Structures of Halide Adlayers and Anodic Dissolution, Journal of Electroanalytical Chemistry 473 (1999) 10-18.

[62] W.H. Li, Y. Wang, J.H. Ye, S. F. Y. Li, In Situ STM Study of Chloride Adsorption on $\mathrm{Cu}(110)$ Electrode in Hydrochloric Acid Aqueous Solution, Journal of Physical Chemistry B 105 (2001) 1829-1833.

[63] T. Hai Phan, T. Kosmala, K.Wandelt, Potential dependence of self-assembled porphyrin layers on a $\mathrm{Cu}(111)$ electrode surface: In-situ STM study, Surface Science 631 (2015) 207-212.

[64] M. Bettayeb, V. Maurice, L.H. Klein, L. Lapeire, K. Verbeken, P. Marcus, Combined in situ microstructural study of the relationships between local grain boundary structure and passivation on microcrystalline copper, Electrochimica Acta 305 (2019) 240-246. 


\section{Tables}

Table 1 Total number and percentage of occurrences of each type of early intergranular corrosion behavior for various types of grain boundaries for microcrystalline copper in $10 \mathrm{mM}$ $\mathrm{HCl}(\mathrm{aq})+1 \mathrm{mM} \mathrm{MBI}$

\begin{tabular}{|c|c|c|c|c|}
\hline $\begin{array}{l}\text { Intergranular } \\
\text { behavior }\end{array}$ & CTs & Low $\Sigma$ CSLs & High $\Sigma$ CSLs & $\begin{array}{c}\text { Random } \\
\text { GBs }\end{array}$ \\
\hline $\begin{array}{c}\text { No preferential GB } \\
\text { activity }\end{array}$ & 5 & -- & -- & -- \\
\hline $\begin{array}{c}\text { Imperfect } \\
\text { protection by } \\
\text { anodically formed } \\
\text { MBI layer } \\
\text { (mitigated } \\
\text { dissolution) }\end{array}$ & 1 & 1 & 3 & 5 \\
\hline $\begin{array}{l}\text { Protection by } \\
\text { corrosion products }\end{array}$ & -- & 3 & 1 & 12 \\
\hline $\begin{array}{c}\text { Transient } \\
\text { protection by } \\
\text { corrosion products }\end{array}$ & 1 & 1 & 1 & 31 \\
\hline $\begin{array}{l}\text { Delayed protection } \\
\text { by corrosion } \\
\text { products }\end{array}$ & -- & 1 & -- & 8 \\
\hline
\end{tabular}




\section{Figure captions}

Figure $1 \mathrm{CV}$ analysis of macroscopic electrochemical behavior of microcrystalline copper in $10 \mathrm{mM} \mathrm{HCl}(\mathrm{aq})($ ECTM cell, scan rate $=1 \mathrm{mV} / \mathrm{s}$ ): (a) CVs recorded without and with $1 \mathrm{mM}$ $\mathrm{MBI}$ in the solution. (b) Enlarged CVs obtained in the presence of MBI after cathodic pretreatment with and without $\mathrm{MBI}$ in the solution. In (b), the $\mathrm{CV}$ obtained in $10 \mathrm{mM} \mathrm{HCl}(\mathrm{aq})+$ $0.1 \mathrm{M}$ MBT is shown for comparison.

Figure 2 Topographic ECSTM images of microstructure obtained at $\mathrm{E}=-0.45 \mathrm{~V} / \mathrm{SHE}$ in $10 \mathrm{mM} \mathrm{HCl}(\mathrm{aq})+1 \mathrm{mM} \mathrm{MBI}\left(\mathrm{Z}\right.$ range $\Delta \mathrm{Z}=6 \mathrm{~nm}$, tip potential $\mathrm{E}_{\text {tip }}=-0.5 \mathrm{~V} / \mathrm{SHE}$, tunneling current $I_{t}=0.6 \mathrm{nA}$ ): (a) Initial surface state; (b) Surface state after $2 \mathrm{CV}$ treatments; (c) Surface state after $4 \mathrm{CV}$ treatments.

Figure 3 Average topographic line profiles measured across the GB at site \# 1 in Figure 2 after 0,2 and $4 \mathrm{CV}$ treatments.

Figure 4 ECSTM evaluation of the intergranular behavior in the early stage corrosion of microcrystalline copper sites in $10 \mathrm{mM} \mathrm{HCl}(\mathrm{aq})+1 \mathrm{mM} \mathrm{MBI}$ : (a) Topographic image with GB sites labelled 1 to 74; (b) Bar graph of the GB depth measured across the sites (labelled in white in (a)) showing no preferential reactivity after 2 and $4 \mathrm{CVs}$; (c) Bar graph of the GB sites (labelled in yellow in (a)) showing depth increase after 2 and 4 CVs; (d) Bar graph of the GB sites (labelled in dark blue in (a)) showing depth decrease after 2 and $4 \mathrm{CVs}$; (e) Bar graph of the GB sites (labelled in black in (a)) showing depth decrease and subsequent increase after 2 and $4 \mathrm{CVs}$, respectively. (f) Bar graph of the GB sites (labelled in light blue in (a)) showing depth increase and subsequent decrease after 2 and $4 \mathrm{CVs}$, respectively.

Figure 5 Schematic illustration of observed MBI inhibiting effects on early intergranular corrosion of copper in acid electrolyte.

Figure 6 Percentage of each type of early intergranular corrosion behavior observed on various types of grain boundaries for microcrystalline copper in $10 \mathrm{mM} \mathrm{HCl}(\mathrm{aq})+1 \mathrm{mM} \mathrm{MBI}$ and comparison in $10 \mathrm{mM} \mathrm{HCl}(\mathrm{aq})+0.1 \mathrm{mM} \mathrm{MBT}$ 
Figure 1

a

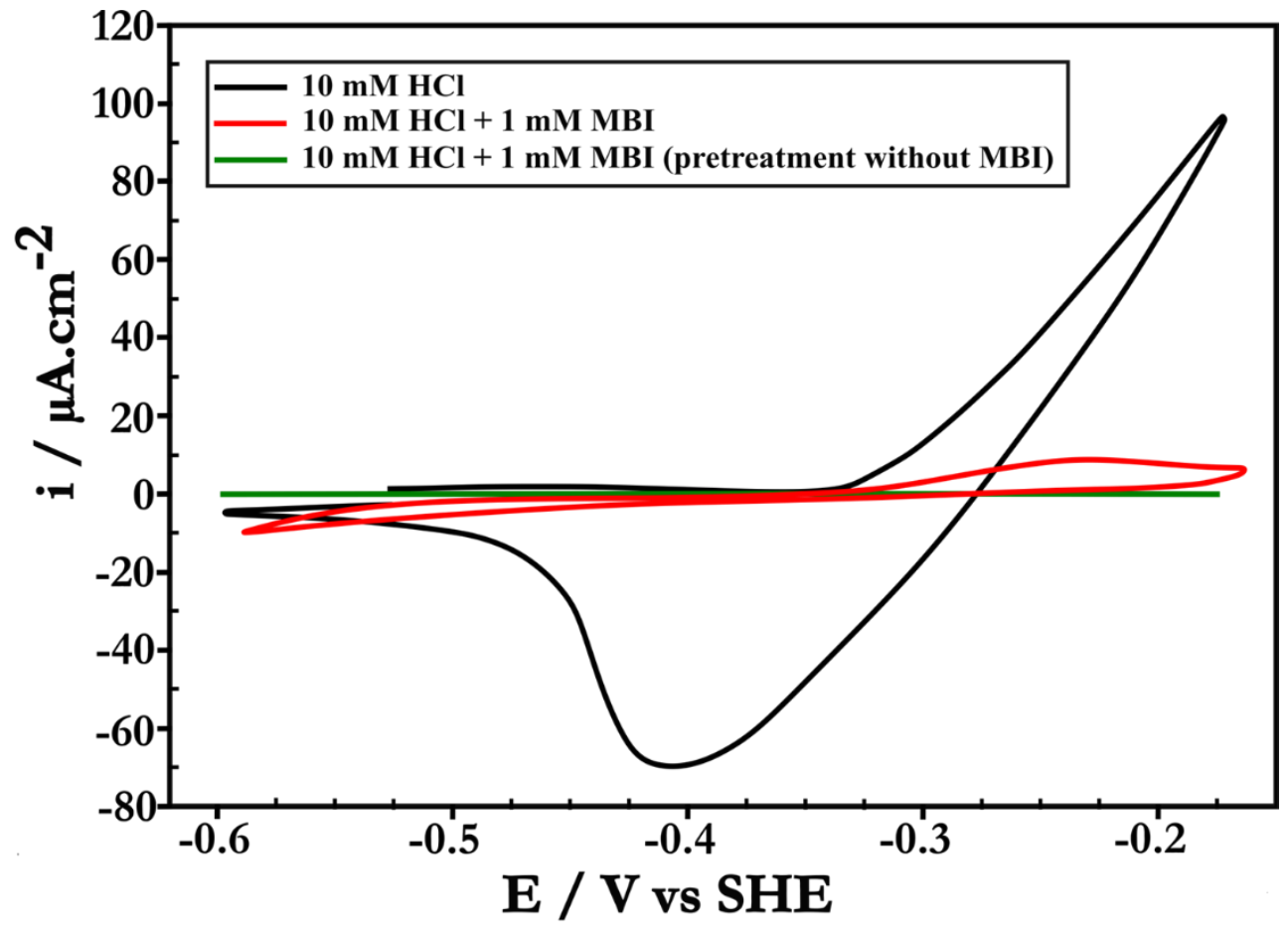

b

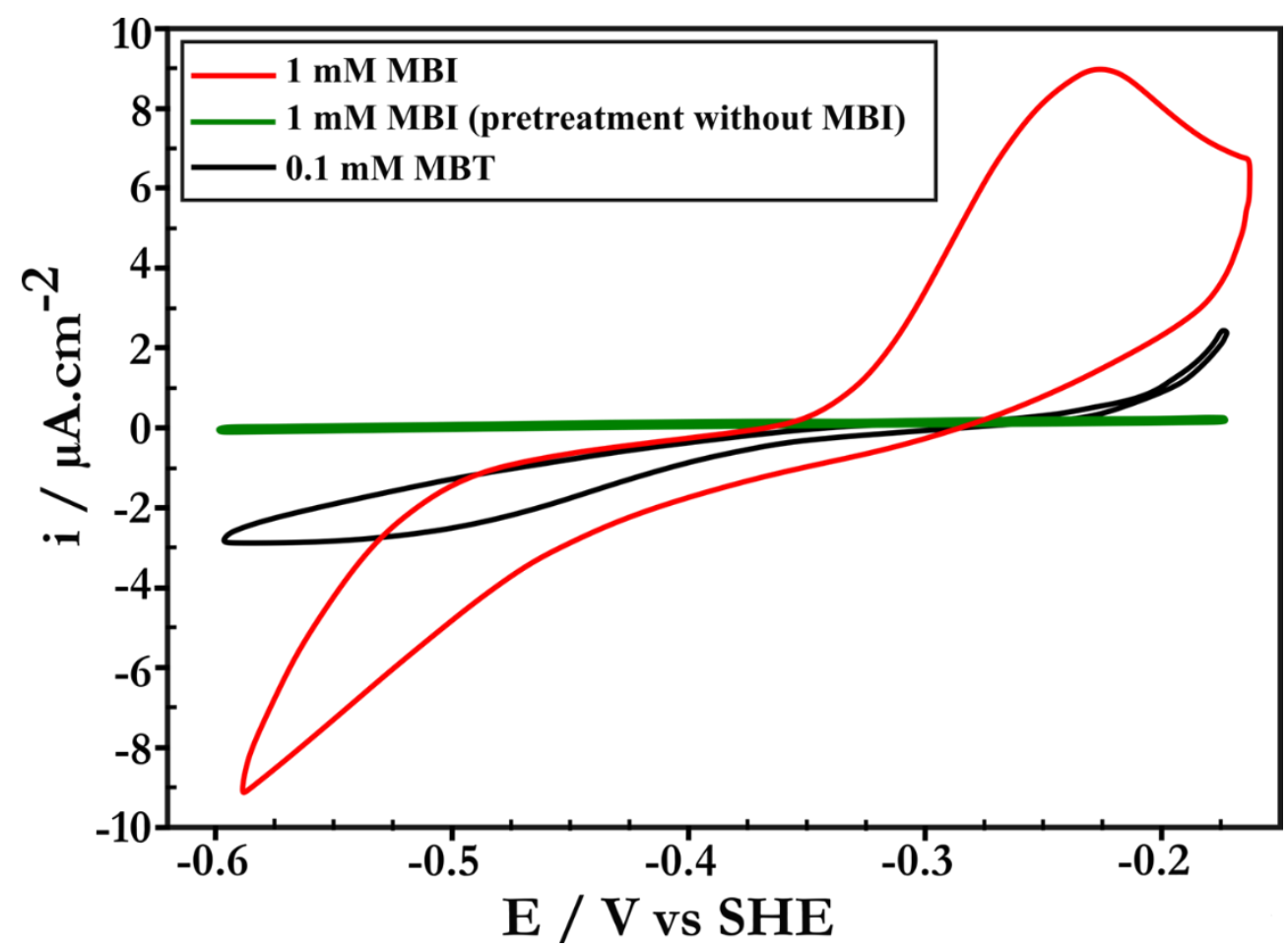


Figure 2
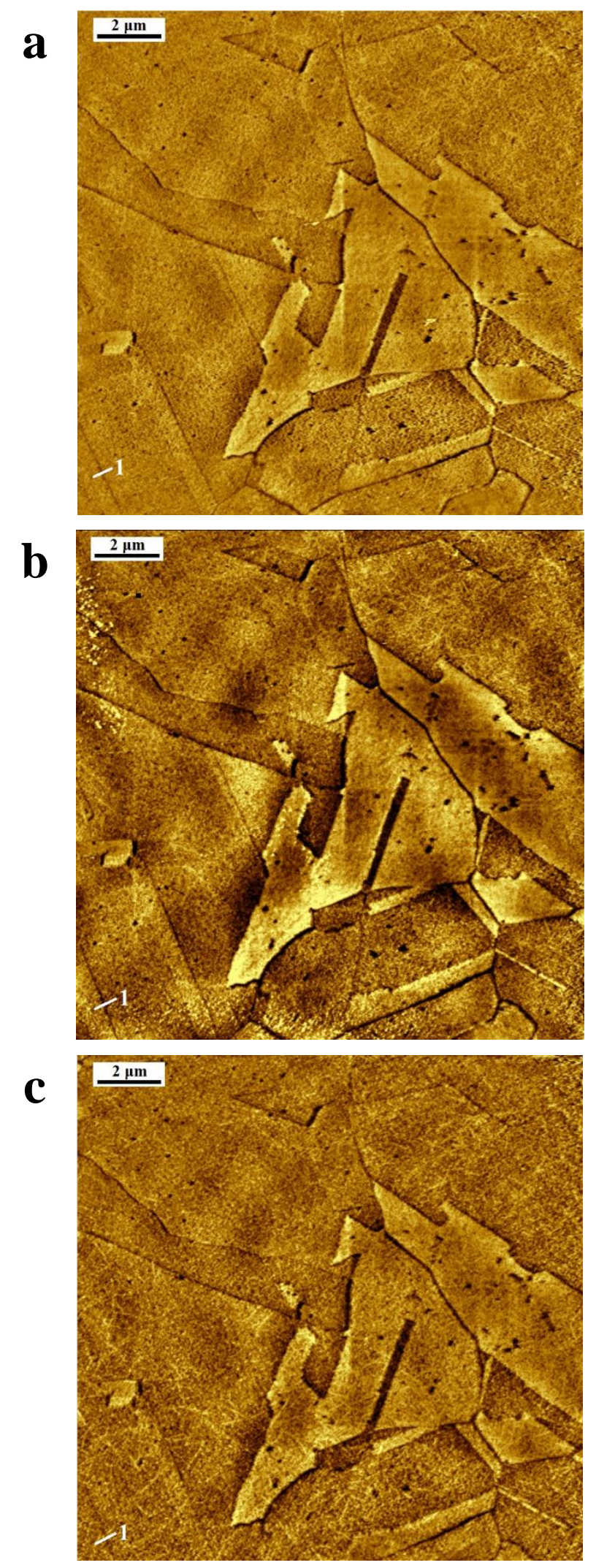
Figure 3

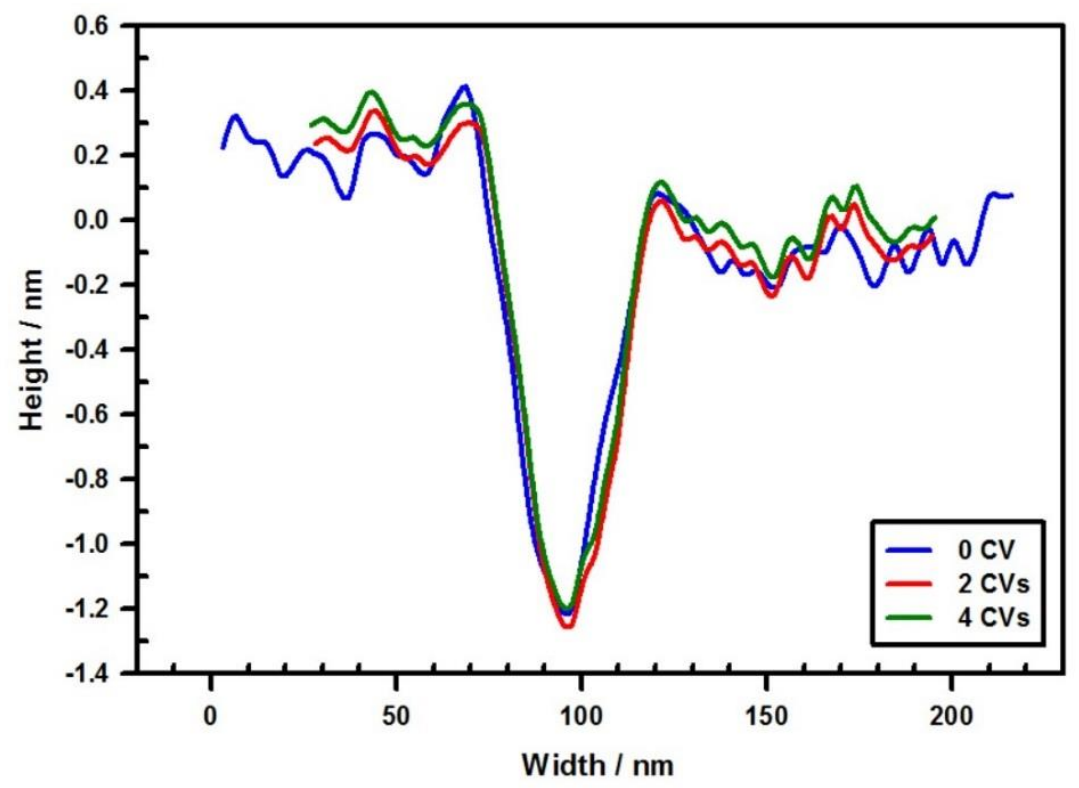


Figure 4
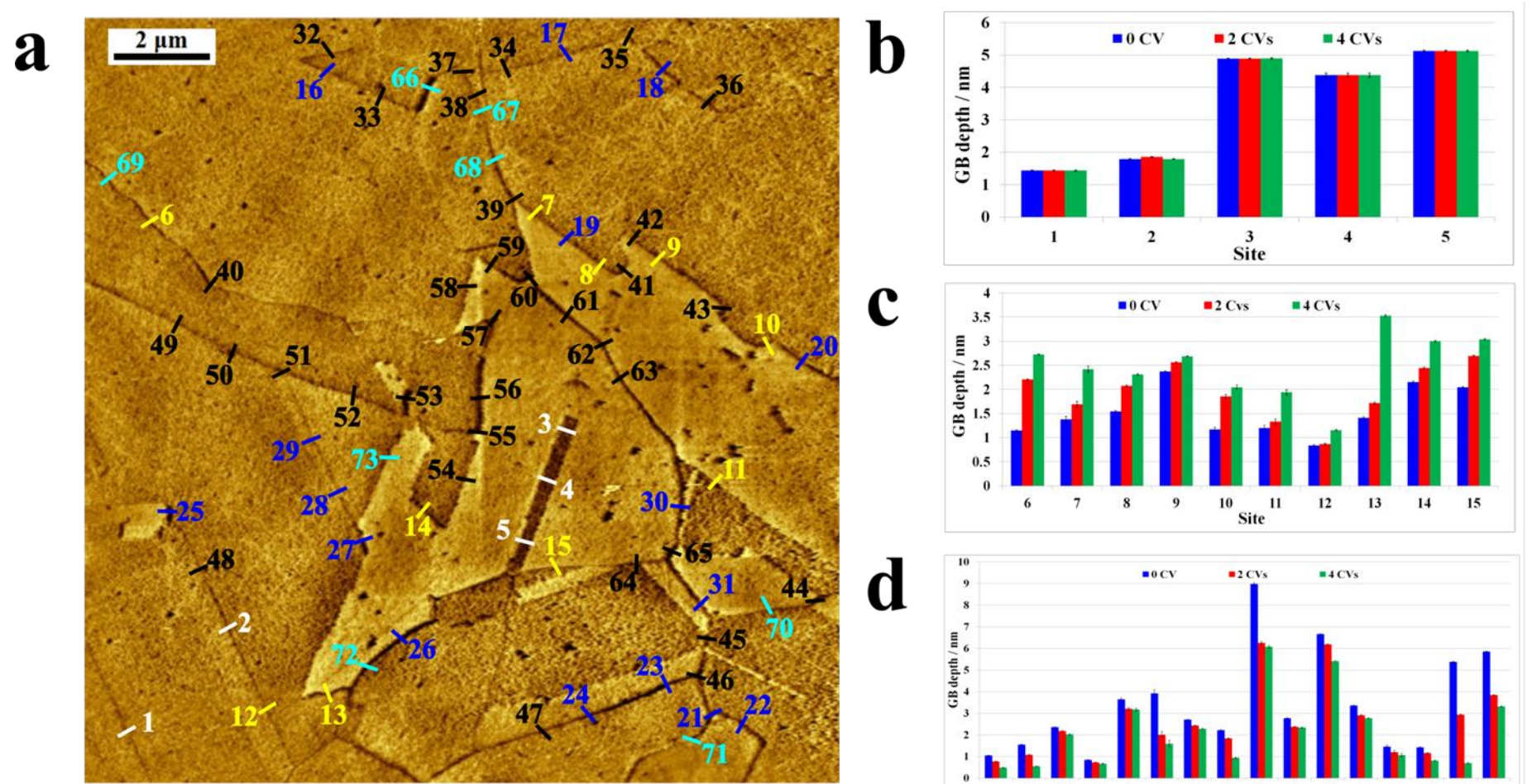

c

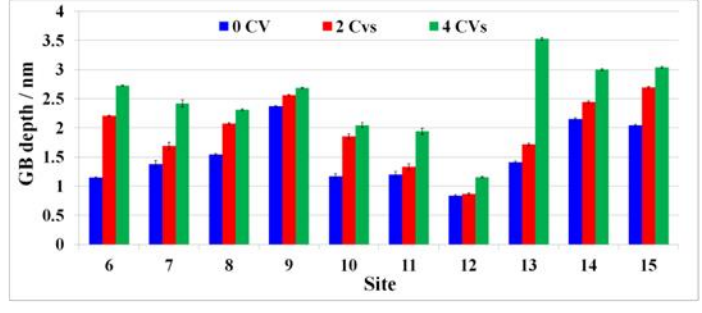

d

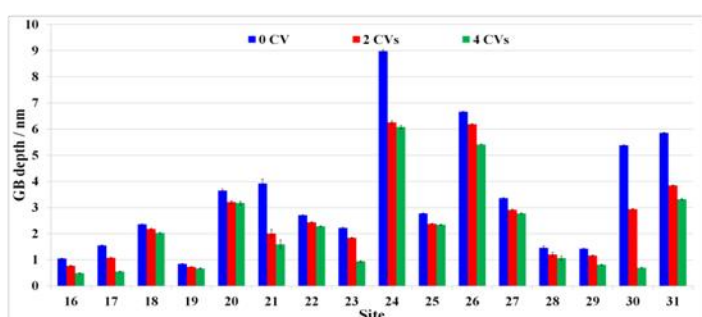

e
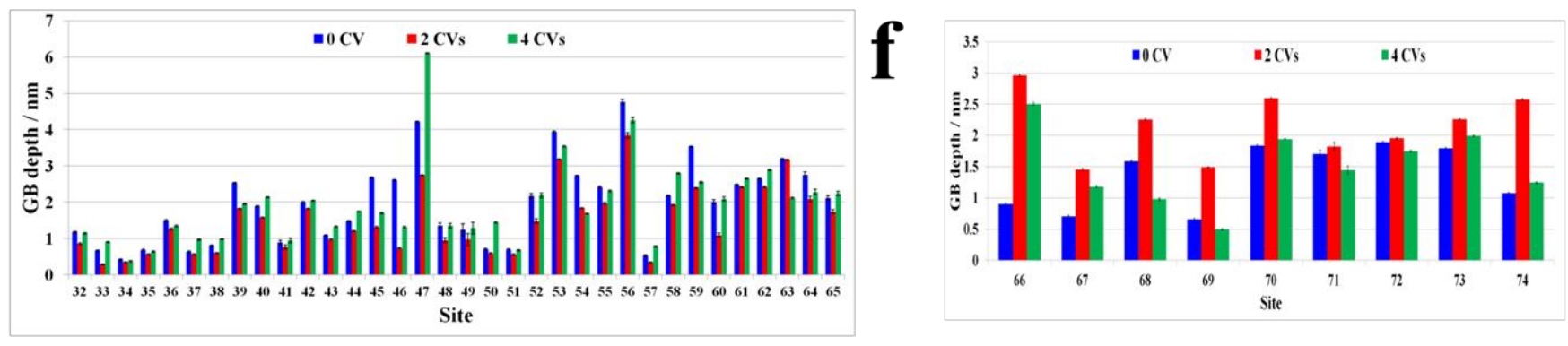


\section{Figure 5}

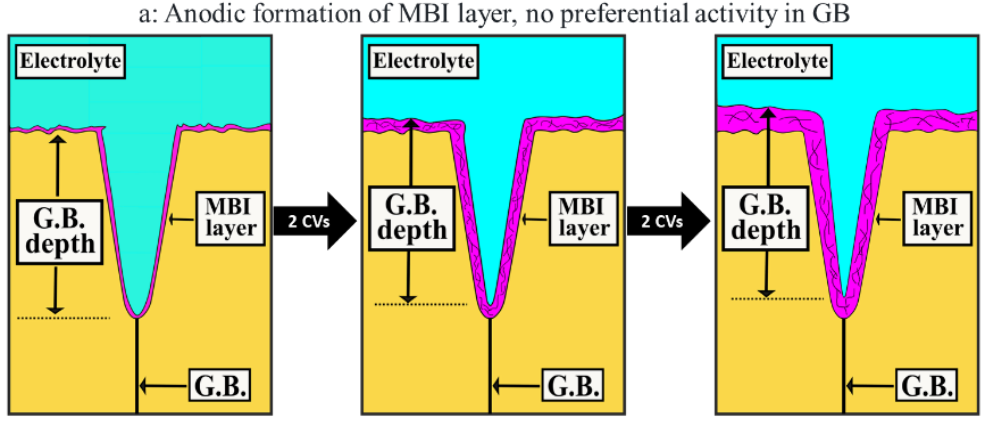

b: Imperfect GB protection by anodically formed MBI layer (mitigated dissolution)

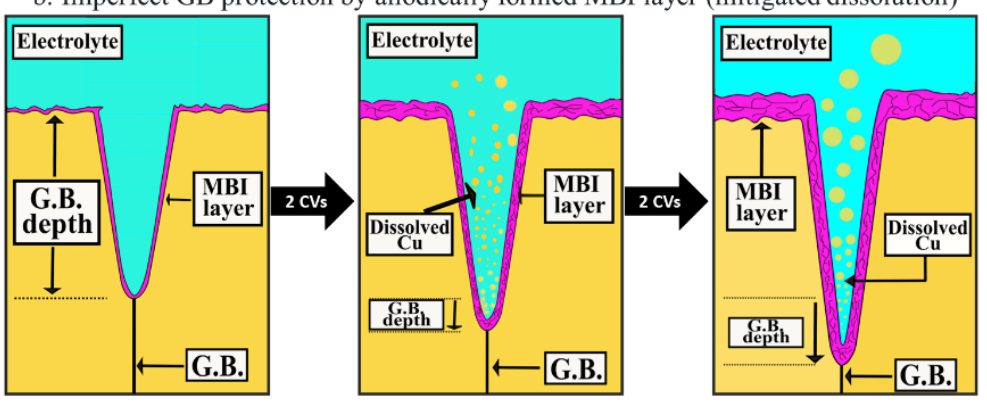

c: GB protection by corrosion products (blocked dissolution)

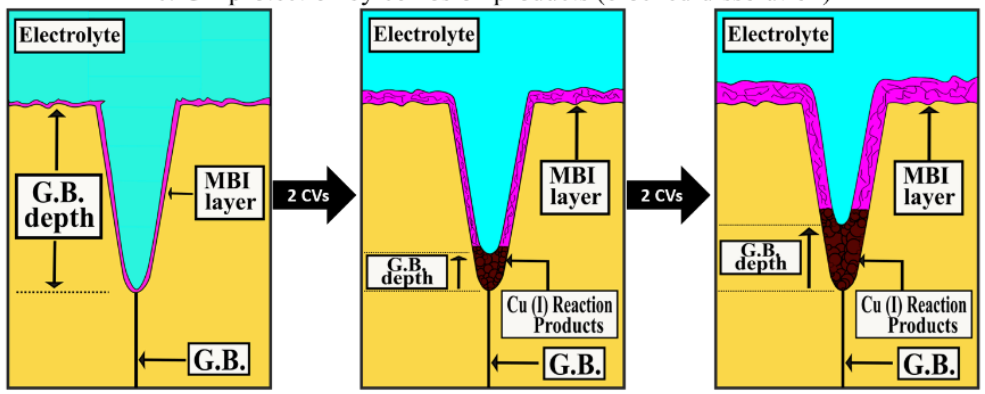

$\mathrm{d}$ : Transient GB protection by corrosion products

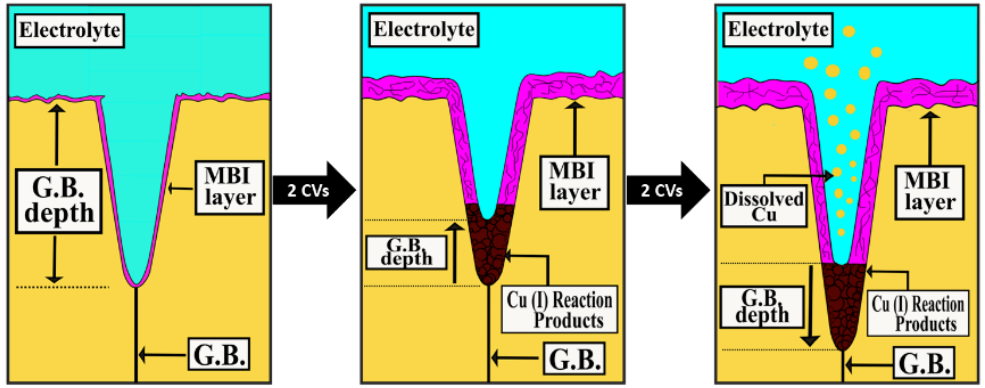

e: Delayed GB protection by corrosion products

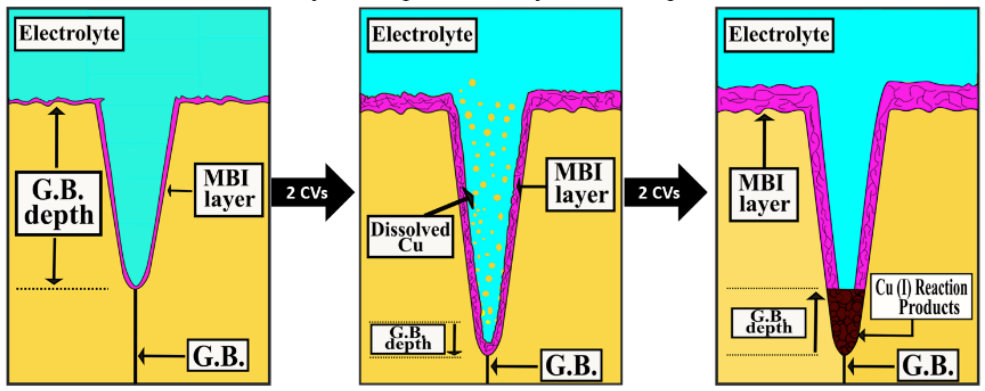




\section{Figure 6}

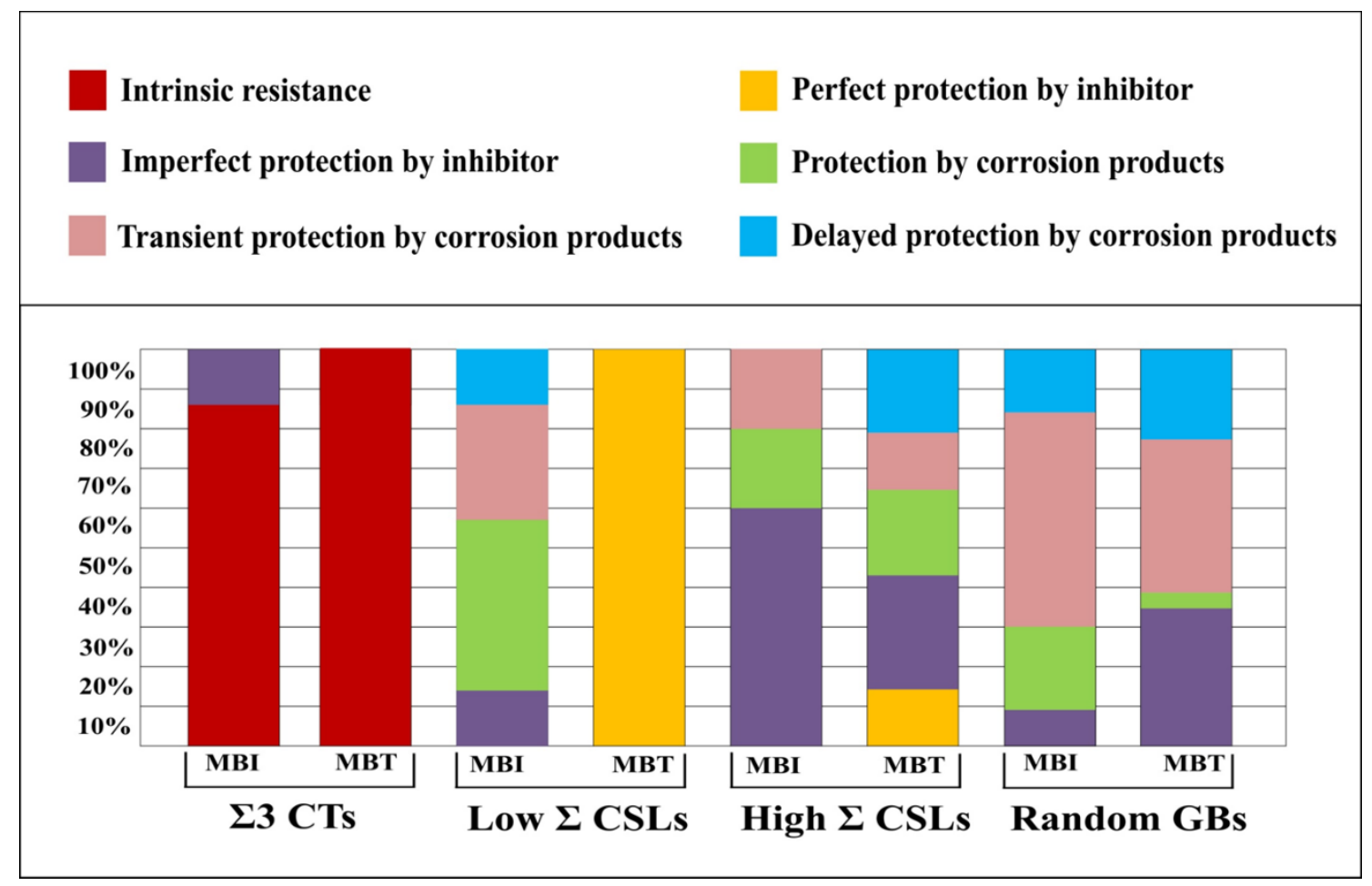

